\title{
OS RESÍDUOS ELETROELETRÔNICOS NO BRASIL E NO EXTERIOR: DIFERENÇAS LEGAIS E A PREMÊNCIA DE UMA NORMATIZAÇÃO MUNDIAL
}

\author{
Lindsay Teixeira Sant'Anna \\ Mestranda em Administração Pública na Universidade Federal de Lavras \\ lindsaysantanna@yahoo.com.br \\ Rosa Teresa Moreira Machado \\ Professora na Universidade Federal de Lavras \\ rosateresa67@gmail.com \\ Mozar José de Brito \\ Professor na Universidade Federal de Lavras \\ mozarbrito@gmail.com
}

\section{RESUMO}

Diante do crescimento exacerbado dos resíduos de equipamentos eletroeletrônicos (REEE) e da ausência de uma política brasileira estruturada que defina as responsabilidades necessárias à organização de uma cadeia reversa de eletroeletrônicos, escolheu-se comparar as legislações dos maiores geradores de REEE do mundo: Estados Unidos, China, Índia e Brasil, bem como de um país pioneiro em gestão de REEE, a Suíça. Por meio de uma pesquisa qualitativa, efetuou-se uma revisão bibliográfica sistemática que identificou semelhanças e divergências legislativas acerca da gestão de REEE entre os países comparados. Este estudo indica ainda a necessidade de uma normatização brasileira que defina os papéis de cada ator envolvido na gestão de REEE, bem como as regras mundiais que facilitem a cooperação internacional no compartilhamento de tecnologias de reciclagem e processos de produção e o descarte sustentável de REEE.

Palavras-chave: Gestão; Logística reversa; Legislação; Normatização mundial; Resíduos de equipamentos eletroeletrônicos.

\section{E-WASTE IN BRAZIL AND ABROAD: LEGAL DIFFERENCES AND THE URGENT NEED OF A GLOBAL STANDARDIZATION}

\begin{abstract}
Facing the overgrowth of electric and electronic waste (e-waste) and the absence of a structured Brazilian policy that defines the responsibilities to the organization of a reverse chair of electronics, this article compares laws from The United States, China, India (all of which are large generators of e-waste) and Switzerland (pioneer country in e-waste management) to the homeland legislation. Through qualitative research, a systematic literature review was adopted, which identified similarities and differences within legislation regarding electronic waste management among the countries. This study also indicates the need for a Brazilian standardization that defines the roles of stakeholders involved in e-waste management, as well as global standardization to facilitate an international cooperation in the sharing of recycling technologies and production processes and sustainable disposal of e-waste.
\end{abstract}

Key words: E-waste; Global standardization management; Legislation; Reverse logistic. 


\section{INTRODUÇÃO}

Compatibilizar crescimento econômico com respeito ao meio ambiente é um desafio que ainda parece estar longe de ser equacionado pelo sistema capitalista. Ao privilegiar interesses econômicos em detrimento das questões ambientais e sociais, sua lógica contraria os fundamentos da sustentabilidade da vida presente e das gerações futuras. A geração cada vez maior de resíduos de equipamentos eletroeletrônicos (REEE), por exemplo, tem suas raízes na obsolescência planejada dos produtos, no encurtamento de sua vida útil e na inovação tecnológica que torna o novo já ultrapassado. Esses fatores, somados a uma crescente sociedade de consumo e à falta de planejamento do Estado para gerenciar os resíduos advindos do descarte de produtos eletroeletrônicos, evidenciam esse caráter insustentável.

Só no Brasil são gerados por ano 680.000 (seiscentos e oitenta mil) toneladas de REEE (Feam, 2013). Um fator preocupante é o potencial de contaminação desses resíduos, já que substâncias, tais como o chumbo, cádmio, mercúrio, bifenilas policloradas (PCBs) e éter difenil polibromado (PBDE) são todas encontradas em componentes eletroeletrônicos que passam a ter contato direto com os catadores, o solo, a água e o ar desencadeando uma contaminação generalizada do local (Wang et al, 2009; Robinson, 2009). Quanto aos efeitos dessas substâncias em contato com o corpo humano, Vaishnav e Diwan (2013) apontam em seus estudos consequências irreversíveis da acumulação em rins, fígado, ocorrência de danos cerebrais, doenças respiratórias e de pele.

A expressão popular "lixo eletrônico" é comumente usada para definir os produtos eletrônicos após o fim de sua vida útil. Porém, a terminologia mais adequada para computadores, celulares e eletrodomésticos descartados é a de REEE, uma vez que, apesar de existirem substâncias perigosas embutidas em tais produtos, há também metais de alto valor que podem ser recuperados e fazer parte novamente do ciclo de produção (Dwivedy e Mittal, 2012). Prova disso é que alguns países da África e Ásia (China, Paquistão e Índia) estão importando em torno de $70 \%$ (setenta por cento) dos REEEs fora de uso no mundo, a fim de reutilizar os equipamentos em programas de inclusão digital ou aproveitar partes deles devido ao valor econômico dos materiais envolvidos (Bachi, 2013).

No Brasil, após 21 anos de tramitação no Congresso Nacional, foi promulgada, em 2010, a Lei n. ${ }^{\circ} 12.305$ que institui a Política Nacional dos Resíduos Sólidos (PNRS) com o objetivo de promover o gerenciamento ambiental adequado dos resíduos sólidos de forma isolada pelo Governo Federal ou em regime de cooperação entre Estados, Distrito Federal, Municípios ou particulares (Brasil, 2013).

Apesar de o Brasil possuir norma legal que proíbe (art.49, PNRS) a importação de resíduos sólidos perigosos (como os componentes de REEE), o cenário brasileiro não é muito animador, já que o país é o maior gerador de REEE entre os países emergentes (Pnuma, 2013) e o seu sistema de gestão do lixo eletrônico é ineficiente e ainda não há regulamentação específica na PNRS sobre o tratamento dos REEEs. Somado a isso, a PNRS encontra dificuldades em sua implementação no que se refere à coleta, à reciclagem e à logística reversa de diversos resíduos, principalmente os eletroeletrônicos (Demajorovic e Migliano, 2013; Oliveira, Bernardes e Gerbase, 2012). Nem mesmo a definição do que seja REEE a PNRS trouxe em seu bojo legal. Ademais, estudos apontam que ainda são escassas as pesquisas sobre os resíduos eletroeletrônicos no Brasil, principalmente no que diz respeito à gestão adequada da logística reversa desses resíduos (Franco e Lange, 2011; Demajorovic e Migliano, 2013).

Por outro lado, a questão da globalização impede que se fale em plena autonomia e isolamento dos países, visto que decisões de produção, consumo, descarte e política podem criar situações insustentáveis em ecossistemas produtivos em locais distantes. Assim, a sustentabilidade de um país tem sido cada vez mais dependente da de outros e um problema como os REEEs tornase um problema global (Kissinger, Rees e Timer, 2011). 
Diante das lacunas na legislação brasileira de resíduos sólidos, como a gestão de REEE tem sido normatizada no âmbito internacional? Algum aspecto jurídico encontrado nas experiências internacionais pode ser aplicado ao Brasil?

Nesse contexto, Queiruga, González e Lannelongue (2012) e Li et al (2013) destacam que a ausência de um método padronizado mundial de gestão de REEE é responsável por grandes diferenças no tratamento desses resíduos nos países. Enquanto alguns nem possuem legislação geral sobre o tratamento dos REEEs (como nos Estados Unidos), outros países apresentam normas sem qualquer articulação com os agentes da cadeia de produção e consumo (como a China, Índia e Brasil); em outro extremo, o sistema de gestão de REEE da Suíça é reconhecido como um modelo bem-sucedido e referenciado mundialmente. Assim, Li et al (2013) sugerem a criação de um mecanismo internacional de apoio por meio de contribuições e troca de tecnologia entre os países de origem dos REEEs, a fim de se equalizar o problema global.

Uma vez que a gestão de REEE é um tema global, escolheram-se os três países que se destacam nesse cenário para, ao final, comparar suas legislações com a brasileira. As razões que justificaram a escolha dos países são as seguintes: Estados Unidos, por ser o maior gerador de REEE do mundo (Herat e Agamuthu, 2012); China, embora esteja na segunda posição, é um dos países de maior potencial gerador de REEE nos próximos anos em razão do seu ritmo crescente de industrialização, além de ser considerado o maior lixão internacional de resíduos eletrônicos (Pnuma, 2013); na sequência vem a Índia, país com a maior taxa mundial de crescimento da indústria eletrônica (Herat e Agamuthu, 2012), e Suíça, por ser um país-modelo na gestão de REEE e pioneiro em legislar sobre a matéria no mundo (Khetriwal, Kraeuchi e Widmer, 2009; Queiruga, González e Lannelongue, 2012).

Dessa forma, o objetivo deste artigo é o estudo dos marcos legais que regulamentam as experiências internacionais de gestão de REEE, na Suíça, Índia, China e Estados Unidos, a fim de compará-los com a legislação brasileira, além de contribuir para a compreensão do cenário normativo brasileiro e mundial sobre gestão de REEE.

Trata-se, portanto, de uma pesquisa qualitativa baseada em um levantamento bibliográfico (desk research) amplo e sistematizado de artigos científicos junto ao acervo de periódicos da Coordenação de Aperfeiçoamento de Pessoal de Nível Superior (Capes), em especial publicados nos últimos cinco anos nas bases Scielo, Scopus e Web of Sciense, a fim de se referenciar pesquisas atuais sobre o tema. Também foram consultados livros relevantes e sites oficiais dos governos dos países estudados. A pesquisa ao acervo de periódicos da Capes se deu entre 23 de junho de 2013 a 13 de agosto de 2013 e a pesquisa, em livros e sites oficiais, se deu até agosto de 2014.

Após as descrições dos marcos legais sobre a gestão de REEE de cada país escolhido e algumas ponderações acerca da aplicabilidade das normativas, passa-se para a aplicação do método comparativo de análise de resultados para revelar as diferenças e convergências entre as legislações dos países. Em cada país são discutidas as principais questões que envolvem os diferentes tratamentos legislativos, as falhas normativas e a ineficiência da gestão de REEE. Na conclusão da pesquisa é realizado um panorama sintético de comparações legais entre os países estudados e reflexões acerca de possíveis pontos a serem observados, para a condução de uma melhor normatização nacional e mundial sobre o gerenciamento dos REEEs.

\section{O PANORAMA LEGAL DOS PAÍSES}

Antes da apreciação dos marcos regulatórios internacionais sobre REEE, é importante mencionar um acordo internacional comum a todos os países aqui estudados: a Convenção de Basileia, realizada na Suíça, sobre o controle de movimentos transfronteiriços de resíduos perigosos e seu depósito (Control of Transboundary Movements of Hazardous Wastes). Em vigor desde 1992, essa convenção foi assinada por 165 países, incluindo os países aqui estudados, com exceção dos Estados Unidos da América. Em sua essência, trata-se de uma cooperação entre países para o 
gerenciamento de resíduos perigosos, tipificando como crime a importação e exportação de tais resíduos para países sem estrutura técnica para recebê-los (Basel Convention, 2013).

A descrição dos marcos regulatórios sobre REEE dos países selecionados acompanha a ordem cronológica da legislação aprovada em cada um deles, com a data assinalada logo após o nome no subtítulo. Apesar de os Estados Unidos não apresentar legislação federal sobre REEE, já que pelo federalismo norte-americano seus Estados são independentes da União para legislar sobre os REEEs em seus territórios, considerou-se o ano de 2003 como marco regulatório no país, levando-se em consideração o ano de edição da legislação na Califórnia, o primeiro estado a regular a matéria.

\subsection{Suíça (1998)}

A Suíça é país signatário e ratificou (1990) a Convenção de Basileia e desde 1998 possui legislação criada pelo chamado "Swiss Federal Office for the Environment (FOEN), por meio da ORDEE - The Return, the Taking Back and the Disposal of Electrical and Electronic Equipment (Portaria sobre retorno dos equipamentos elétricos e eletrônicos) que trata especificamente sobre a gestão de lixo eletrônico, sendo pioneira nessa seara. No entanto, a coleta e gestão dos REEEs começaram até mesmo antes de a legislação entrar em vigor, em 1990, por meio da Swiss Foundation for Waste Management, uma iniciativa voluntária de responsabilidade dos produtores. Os produtores fazem parte dessa organização que representa as diversas empresas produtoras de eletroeletrônicos. E é exatamente nessa ação voluntária, oriunda da articulação entre os atores envolvidos na cadeia de logística reversa do produto eletroeletrônico, que se revela o sucesso do sistema suíço (Khetriwal; Kraeuchi e Widmer, 2009; Wager; Hischier e Eugster, 2011). Dessa forma, quando o governo suíço decidiu regulamentar a gestão de REEE já existia um modus operandi anterior no mercado que garantia a reciclagem, cabendo ao Estado formalizar aquilo que já acontecia na prática, além de especificar responsabilidades e o procedimento de cobrança da taxa de custeio da logística reversa.

Para Khetriwal, Kraeuchi e Widmer (2009), o elemento essencial do sistema de gestão do lixo eletrônico suíço é que o mesmo é baseado na responsabilidade estendida do produtor, conhecida como Extended Producer Responsability (EPR), com uma definição clara dos papéis e das responsabilidades de todas as partes envolvidas. Essa responsabilidade é estendida, porque o fabricante do produto é responsável por toda a vida útil do produto, inclusive por sua reciclagem e disposição final. No entanto, essa responsabilidade é compartilhada entre todos os envolvidos (governo, fabricantes, importadores, distribuidores, varejistas, consumidores, pontos de coleta e recicladores).

O governo federal suíço faz o papel de um supervisor, editando as leis e definindo as diretrizes básicas, enquanto as autoridades locais desempenham o papel de monitoramento da qualidade dos serviços prestados pelos recicladores licenciados. Os fabricantes e importadores têm o papel de gerenciar as operações do dia-a-dia do sistema, incluindo a definição das taxas de reciclagem e licenciamento e a realização de auditoria nos recicladores. Os distribuidores e revendedores são obrigados a receber os produtos, mesmo que não os tenham vendido. Por lei, os consumidores são obrigados a levar os aparelhos descartados para as lojas ou pontos de coleta. $\mathrm{O}$ consumidor, que tem a responsabilidade financeira final, ao comprar um produto novo desembolsa uma taxa denominada de Advanced Recycling Fee -ARF (taxa antecipada de reciclagem). Os pontos de coleta, por sua vez, são obrigados a transportar o REEE gratuitamente até os recicladores e garantir sua segurança contra furtos e exportações ilegais (Khetriwal, Kraeuchi e Widmer , 2009; Ongondo; Williams e Cherret, 2011).

Assim, o modelo suíço de gestão do REEE impõe um ônus demasiadamente alto ao consumidor, uma vez que o preço do produto eletroeletrônico no varejo inclui, pelo menos, duas taxas, a do fabricante (que é transferida para os agentes do canal de distribuição), somada à taxa paga pelo consumidor. Ou seja, o preço para o consumidor sai duplamente mais caro.

Revista de Gestão Social e Ambiental - RGSA, São Paulo, v. 8, n. 1, p. 37-53, jan./abr., 2014. 
A Suíça possui uma legislação, a Ordinance on the Publication of Prices de 1978 (Portaria sobre a Publicação de Preços), que obriga os varejistas a informar aos clientes sobre o preço final do produto, que já contém a taxa embutida. No entanto, não são obrigados a especificar o valor exato embutido no preço referente à taxa (Khetriwal, Kraeuchi e Widmer, 2009).

Por fim, os recicladores (unidades de reciclagem) devem respeitar normas mínimas de segurança e saúde do empregado e precisam de autorização do governo local para operar uma unidade, bem como a licença dos profissionais, além de terem seus contratos cancelados e licenças revogadas caso descumpram a legislação (Khetriwal, Kraeuchi e Widmer, 2009).

Como solução originalmente criada e compartilhada pelos próprios fabricantes, embora o modelo de gestão suíço seja referência mundial, ressalta-se, no entanto, que sua mera importação não é o melhor caminho para países com realidades tão diferentes como os escolhidos neste estudo. Neste contexto, alguns fatores, tais como dimensões territoriais, sistemas de governo, desenvolvimento socioeconômico e ausência de tecnologia para separação de materiais de valor agregado aos REEEs, devem ser considerados antes da implantação de um modelo.

\subsection{China (2003)}

Embora signatária da Convenção de Basileia, até 2003, a China possuía somente uma lei de 1995 sobre prevenção da poluição ambiental por resíduos sólidos, mas não especificamente sobre REEE. Em 2003, a Agência de Proteção Ambiental promulgou uma declaração sobre o fortalecimento da gestão dos REEEs, recomendando aos órgãos de proteção local o controle da poluição em atividades de descarte e reciclagem de lixo eletrônico. Por meio dessa declaração surgiram dois regulamentos em forma de portarias, uma em 2006 (Technical Policy on Pollution Prevention and Control of Waste Electrical and Electronic Products) e a outra em 2007 (Administrative Measures for the Prevention and Control of Environmental Pollution by Electronic Waste), sobre controle e prevenção da poluição por REEE, respectivamente. O país incorporou na Lei de Promoção da Economia da República Popular da China (2008) o princípio da responsabilidade estendida do produtor (fabricante), que se refere à responsabilização pós-consumo pelo produto colocado no mercado. O governo chinês afirma que, ao exigir que o fabricante assuma a responsabilidade parcial ou total pelo descarte do lixo eletrônico, se aumenta a consciência ambiental e preocupação pela utilização de materiais recicláveis na produção (Chinese, 2013).

Em 2009 foi promulgada a lei chinesa sobre gestão de REEE, a Ordinance on the Administration of the Recovery and Disposal of Waste Electrical and Electronic Products (Portaria sobre Administração e Eliminação de Resíduos Elétricos e Eletrônicos), que entrou em vigor só em 01 de janeiro de 2011. A partir dela, em maio de 2012 na cidade de Pequim, o Ministério das Finanças anunciou medidas de arrecadação e administração dos fundos para eliminação de lixo eletrônico e elétrico, que foram implementadas em julho do mesmo ano. A responsabilidade dos fabricantes e importadores se limita às contribuições (por meio de taxas) para um fundo gestor do governo, com o objetivo de subsidiar a reciclagem e o tratamento do REEE. Entende-se, portanto que, na China, embora fabricantes e importadores paguem taxas para contribuir com a formação de um fundo de reciclagem de REEE, eles também são beneficiados com subsídios governamentais para implantar a reciclagem de REEE (Chung e Zhang, 2011; Tong e Yan, 2013). Apesar disso, segundo Tong e Yan (2013), tal modelo de responsabilização do fabricante, baseado em taxas e fundos governamentais, tem recebido críticas por não oferecer aos fabricantes incentivos para criação de produtos sustentáveis.

Em janeiro de 2011, a China adotou uma legislação reguladora dos resíduos eletroeletrônicos, por meio da MEP-Administrative Rules of Collection and Disposal Fund of Waste Electrical Appliances and Electronic Products (Portaria de Coleta e Descarte de Resíduos de Aparelhos Eletroeletrônicos), com o objetivo de reduzir o volume global de lixo eletrônico e aumentar sua taxa de reutilização e reciclagem. São explicados no diploma legal conceitos como "reutilizar", "reciclar" e "poluidor-pagador". Ademais, estipulam-se as regras gerais para o 
ecodesign de produtos e informação sobre substâncias tóxicas advindas dos mesmos (Zeng, Stevels e Liu, 2013). No entanto, a questão do controle do uso de resíduos perigosos na produção de eletroeletrônicos na China ainda não é eficaz, já que a legislação somente faz o controle de tais resíduos para produtos de exportação e não há nenhuma constatação de que tal "triagem" é realizada no mercado interno de produtos. Para Chung e Zhang (2011), é necessária uma certificação em todos os produtos eletroeletrônicos produzidos no país que consista numa declaração do fabricante quanto a presença de substâncias perigosas na fabricação dos objetos. Tal informação seria um instrumento informativo ao consumidor que forneceria maior segurança quanto às especificações do produto e aos cuidados exigidos para seu futuro descarte.

É no princípio do "poluidor-pagador" que a legislação ambiental chinesa encontra seu pilar, na medida em que a responsabilidade pelo REEE é compartilhada entre as partes envolvidas na rede de produção e consumo do lixo eletrônico. Os distribuidores são responsáveis pela coleta de lixo eletrônico e por sua entrega aos recicladores; estes são responsáveis pela reutilização, desmontagem e disposição final, e aos consumidores cabe recolher e entregar o seu próprio REEE para os coletores certificados pelo governo (Kojima et al, 2009). No entanto, Zhou e Xu (2012) ressaltam que, ao estabelecer o princípio do "poluidor-pagador", a política chinesa não explicitou as responsabilidades do governo pelo REEE. Além disso, não existe penalidade aos fabricantes de produtos, importadores e varejistas que não instaurarem um sistema de coleta de REEE (Chung e Zhang, 2011).

Assim, denota-se que ainda falta uma política que assegure eficazmente o sistema de devolução dos produtos descartados, com segurança, ao fabricante ou à reciclagem. Ademais, o governo encontra grandes dificuldades em mapear os operadores informais do mercado, devido à falta de registro dos mesmos em organizações do comércio e nas agências do governo. Isso acarreta a suspensão desnecessária de atividades empresariais por falta de coordenação entre as agências chinesas acerca de informações sobre o processo de aprovação do licenciamento de agentes que atuam com a reciclagem de REEE (Chung e Zhang, 2011).

Portanto, de acordo com a literatura consultada, o governo chinês, por um lado, restringe a responsabilidade ao fabricante com o pagamento de uma taxa ao fundo governamental gestor de REEE; por outro, desonera outros atores envolvidos no sistema de logística reversa, tais como os varejistas, recicladores e consumidores.

\subsection{Estados Unidos (2003)}

Nos Estados Unidos (país signatário, mas que não ratificou a Convenção de Basileia) não existe legislação federal que regulamenta a gestão dos REEEs. No entanto, no sistema de jurisdição estadual americano, mais de vinte estados apresentam legislações de gerenciamento de REEE que se baseiam na responsabilidade estendida do produtor pressionando os fabricantes a assumirem a responsabilidade por seus resíduos (Kyle, 2013). Destes, destacam-se treze estados: Califórnia, Connecticut, Havaí, Illinois, Indiana, Maine, Minnesota, New Jersey, Nova York, Carolina do Norte, Oregon, Rhode Island e Carolina do Sul, que proibiram a disposição de vários tipos de eletrônicos em aterro (Herat e Agamuthu, 2012).

A ausência de uma legislação federal nos Estados Unidos se deve ao fato de o lixo eletrônico não ser considerado resíduo perigoso e do país adotar um sistema descentralizado de administração pública, que legitima os estados-membros a normatizar sobre REEE. Dessa forma, a gestão é de responsabilidade de cada estado e, em específico, dos municípios (Wagner, 2009). Apesar de Lepawsky (2012) vislumbrar pontos positivos nesse sistema de jurisdição estadual que possibilita um conjunto dinâmico e múltiplo de normas locais ao contrário de um cumprimento rigoroso de regras gerais, a inexistência de legislação federal demonstra um desinteresse do governo federal ao ignorar a questão das substâncias perigosas contidas nos eletroeletrônicos comercializados. 
O estado da Califórnia foi o primeiro a legislar sobre REEE em 2003, ao estabelecer um sistema de financiamento de coleta e reciclagem de alguns REEEs. Por meio desse sistema, os consumidores pagam uma taxa (destinada ao Estado) no momento da compra do produto que é utilizada para reembolsar os recicladores e coletores (Oliveira, Bernardes e Gerbase, 2012). Se o preço final de um produto no mercado passa a embutir uma taxa extra, isso significa que cabe ao consumidor (pessoa física e/ou jurídica) contribuir para a formação de um fundo destinado a financiar os serviços de coleta e reciclagem. Lepawsky (2012) salienta que, embora 20 dos 24 estados dos EUA que já possuíam legislação sobre REEE até 2010, incluem uma regulamentação para evitar bitributação de taxas sobre o consumidor no fim da vida do produto eletrônico (quando este é devolvido para a reciclagem), nada impede que um agente reciclador a exija no momento da compra do referido produto, externalizando assim os custos da gestão dos REEE ${ }^{1}$.

Ressalta-se que existem estados americanos que atribuem o custo da gestão do REEE aos varejistas. Portanto, nem todos estipulam o sistema californiano de taxa ao consumidor (Towsend, 2011). Dessa forma, o consumidor californiano pode optar por desprestigiar o comércio local e efetuar suas compras em um município de um estado vizinho que não cobre a referida taxa. Esse, inclusive, foi um dos motivos pelo qual o Estado americano de Maine não instituiu a taxa. O receio foi de que seus cidadãos efetuassem suas compras no Estado vizinho de New Hampshire, que não institui a taxa em sua legislação estadual de gestão de REEE (Wagner, 2009). Portanto, a imposição da taxa de reciclagem ao consumidor em um estado pode acarretar um desequilíbrio no comércio das cidades. Se o comércio local não é mais privilegiado, a falência de empresas e desempregos podem ser algumas das consequências locais evidenciáveis.

Wagner (2009) entende que esse sistema municipal de gestão do REEE acaba por submeter os indivíduos e a sociedade norte-americana como um todo a riscos por manuseio e/ou descarte inadequado do lixo eletrônico, visto que a responsabilidade sobre o resíduo fica restrita aos limites políticos de cada município. Desse modo, se um município não possui um processo específico de gestão de REEE, as famílias assumem essa responsabilidade, o que pode levar as pessoas ao risco de uma desmontagem manual inadequada, com implicações nocivas e perigosas à saúde humana e ao ambiente. Admite que tal sistema legislativo, somado a ausência de legislação sobre gestão de REEE em todos os estados americanos, explique a baixa porcentagem, 15\% de reciclagem de REEE nos Estados Unidos.

\section{4 Índia (2003)}

Em 2005, o Conselho de Controle de Poluição da Índia desenvolveu diretrizes para o manejo sustentável do lixo eletrônico na Índia, mas foi somente em 2011 que o Ministério do Meio Ambiente e Florestas propôs um conjunto de regras denominadas de E-waste Management and Handling (Regras de lixo eletrônico: Gestão e Manejo), que entrou em vigor em 01 de maio de 2012 (Herat e Agamuthu, 2012). A nova regra determina a responsabilidade da gestão do lixo eletrônico aos fabricantes, seguindo o raciocínio do princípio da responsabilidade estendida do produtor, e também limita a utilização de resíduos perigosos nos produtos eletroeletrônicos. Entretanto, não há nada normatizado sobre o procedimento de coleta, reciclagem e reutilização dos REEEs. Por outro lado, o governo indiano estabeleceu a diminuição dos espaços para construção de aterros e o aumento do custo da disposição dos REEEs nesses lugares, com o objetivo de estimular a reciclagem dos REEEs pelos fabricantes (Dwivedy e Mittal, 2012).

O que ocorre é que os REEEs têm sido tratados pelo governo indiano como lixo domiciliar, não havendo qualquer tratamento diferenciado e separado dos demais resíduos sólidos produzidos pelas residências. Tal situação não poderia ser diferente, já que as regras de lixo eletrônico (Gestão e Manejo), promulgadas em 2012, não definiram as responsabilidades dos atores envolvidos no ciclo de vida do eletroeletrônico (Dwivedy e Mittal, 2012). Portanto, não havendo o sistema de coleta do REEE, os mesmos são agrupados juntamente com outros resíduos domésticos e tratados como se assim o fossem. 
Apesar de a Índia ser um dos signatários da Convenção de Basileia, o país sofre um surto de importações ilegais de REEE de países desenvolvidos (Dwivedy e Mittal, 2012). O país vem enfrentando sérios problemas com o fluxo de REEE, principalmente no que se refere à contaminação do meio ambiente, em razão da manipulação informal, que também resulta em uma baixa recuperação de materiais (Dwivedy e Mittal, 2012). A informalidade dos mercados, principalmente em cidades como Nova Déli e Bangalore onde empresas vêm explorando a extração dos metais preciosos encontrados em REEE, é responsável por problemas sociais e ambientais. $\mathrm{O}$ interesse econômico associa-se à pobreza e às comunidades locais (incluindo as crianças) que servem de mão de obra na separação dos metais dos eletrônicos obsoletos que são vendidos para sucateiros (Gidarakos et al, 2012).

Outro fator que demonstra a urgência de uma política de gerenciamento do REEE é a gama de produtos montados por empresas de pequena escala, produtos falsificados e contrabandeados. Todos estes atores também precisam ser abrangidos pela política. Nesse sentido, Dwivedy e Mittal (2012) defendem a responsabilidade compartilhada entre todos os fabricantes (de grande escala, pequena escala, de produtos originais, produtos de imitação, etc), o que não é tratado na legislação indiana. Da mesma forma, os autores afirmam que o mercado de produtos de segunda mão não pode ser excluído da política e precisa fazer parte dos mecanismos de incentivos governamentais.

Um sistema de gestão de REEE dificilmente logrará êxito na Índia se não forem estipuladas normas rígidas de saúde e segurança no trabalho, haja vista que o mercado informal de reciclagem absorve milhares de pessoas carentes que anseiam por um trabalho. O elemento humano não pode ser tratado tão-somente como meio para se desfrutar do retorno financeiro da sucata eletrônica; também é preciso levar em consideração a adoção de métodos adequados para o manuseio dos REEEs. Dessa forma, mais urgente que uma legislação para tratar de uma logística reversa que ainda não acontece, é necessária uma regulamentação do funcionamento dessas empresas de reciclagem já instaladas, desde 2002, e em pleno funcionamento na Índia.

\subsection{Brasil (2010)}

Após 21 anos de espera, somente em 07 de julho de 2010 o Congresso Nacional Brasileiro aprovou o Projeto de Lei n ${ }^{\circ}$ 203/91 que institui a Política Nacional de Resíduos Sólidos (PNRS). O projeto de lei 354/1989, que culminou no projeto $\mathrm{n}^{\circ} 203 / 91$, dispunha sobre o acondicionamento, a coleta, o tratamento, o transporte e a destinação final dos resíduos de serviços de saúde. Apresentado pelo então Senador Francisco Rollemberg, o projeto original com 31 artigos, passou a ter 57 na forma final de lei ordinária $n^{\circ} 12.305$, de 2 de agosto de 2010 , que institui a PNRS. No projeto de lei original não havia qualquer menção à logística reversa e aos produtos eletroeletrônicos. Durante a tramitação no Plenário da Câmara, o projeto original sofreu 12 emendas, todas apresentadas no ano de 2010 (Brasil, 2013). A Lei $\mathrm{n}^{\mathbf{0}}$ 12.305/2010 definiu a aplicabilidade do instrumento da logística reversa, com o intuito de promover um eficiente gerenciamento dos resíduos sólidos gerados no país, especialmente o resíduo eletroeletrônico, foco deste estudo.

A PNRS foi regulamentada pelo Decreto Federal $n^{\circ} 7404$ de 23 de dezembro de 2010. Assim, somente entrou em vigor após sua regulamentação, registrando o ano de 2011 como o primeiro ano de vigência da lei. Esta lei é o marco regulatório nacional no setor de resíduos sólidos e é responsável por uma série de conexões normativas com outros diplomas legais, tais como a Política Nacional do Meio Ambiente, a Lei Federal de Saneamento Básico (Lei no 11445/07), a Lei Federal de Consórcios Públicos (Lei n ${ }^{\circ}$ 11.107/05); de Parceria Público-Privada (Lei no 11079/04); do Estatuto da Cidade (Lei $n^{\circ}$ 10257/01) e da Lei de Educação Ambiental (Lei no 9795/99), entre outros textos afins.

A Lei $\mathrm{n}^{\mathrm{o}} 12.305$ institui o princípio da responsabilidade compartilhada pelo ciclo de vida dos produtos, o que abrange fabricantes, importadores, distribuidores, comerciantes, consumidores e titulares dos serviços públicos de limpeza urbana e manejo de resíduos sólidos. O decreto 
regulamentador vem, portanto, cumprir a função de estabelecer normas para execução da lei e definir a responsabilidade compartilhada, de forma individualizada e encadeada, no que diz respeito aos cuidados com a destinação dos resíduos. Neste contexto, a logística reversa, que encontra seu conceito na PNRS, torna-se obrigatória para os fabricantes, importadores, distribuidores e comerciantes de produtos eletroeletrônicos (art. 33, VI) e também para os consumidores que, na presença do instrumento, devem efetuar a devolução dos produtos ou das embalagens objeto da logística $\left(\operatorname{art} .33, \S 4^{\circ}\right)$. A implementação da logística reversa estabelecida pela LRS deve se dar por meio de acordos setoriais e termos de compromisso firmados entre o poder público e o setor empresarial $\left(\operatorname{art} .33, \S 1^{\circ}\right)$. A intenção é estimular a participação e o diálogo entre todos os atores envolvidos na cadeia reversa de REEE. Para tal, a legislação brasileira estabeleceu um prazo de quatro anos para a definição desses contratos de soluções compartilhadas, até o ano de 2014.

O que ocorre é que os próprios envolvidos (fabricantes, importadores, distribuidores, comerciantes, recicladores) não têm conhecimento de seus papéis no processo, muito menos os consumidores que são, em sua grande maioria, desprovidos de qualquer informação acerca dos REEEs. Ademais, mesmo a PNRS deixando clara a cooperação entre União, Estados, Distrito Federal e Municípios, até o momento, somente o estado de São Paulo possui legislação específica sobre REEE. Portanto, não há uma política estruturada e cooperada que contenha diretrizes para a coleta e reciclagem de REEE no Brasil (Oliveira, Bernardes e Gerbase, 2012). A lentidão na implementação da logística reversa de REEE é evidente até agora, meados de 2014. Uma pesquisa com representantes da cadeia reversa que devem compor o acordo setorial previsto na lei aponta que essa lentidão se deve as dificuldades de coordenar interesses e conflitos de atores tão diversos, à dimensão territorial do país, às lacunas tecnológicas, à falta de incentivos fiscais e à presença de cooperativas de catadores e catadores independentes. Tudo isso provavelmente não foi considerado quando da edição da PNRS (Demajorovic e Migliano, 2013).

$\mathrm{O}$ decreto regulamentador ainda define que o poder público pode instituir medidas indutoras e linhas de financiamento para a estruturação do sistema de logística reversa. (art.42, V). A responsabilidade do consumidor é ratificada no art. $6^{\circ}$ do decreto, cabendo a ele a obrigação de acondicionar adequadamente o resíduo que será coletado para reciclagem ou para a devolução ao responsável pela coleta daquele produto, visto que o regulamento deixa claro que a coleta seletiva pode ser implementada independentemente do mecanismo da logística reversa (art.12). O decreto cria o capítulo III destinado ao tratamento normativo da logística reversa, definindo conceito, instrumentos e formas de implementação. As principais novidades trazidas pela norma ficam por conta das opções de compra de produtos ou embalagens usadas e adoção de postos de coleta de resíduos reutilizáveis e recicláveis, dando preferência às cooperativas de catadores $\left(\operatorname{art} .18, \S 1^{\circ}\right)$; Pelo decreto, existe ainda a possibilidade de o Poder Executivo (federal, estadual ou municipal) regular a logística reversa (art. 30) e a composição do Comitê Orientador para implantar o sistema de logística reversa (art. 33). Com o objetivo de garantir sua eficácia, o decreto estabelece penalidades para os casos de descumprimento das obrigações relacionadas à coleta seletiva e logística reversa. Ao cometer o desvio de conduta, em uma primeira vez, o consumidor estará sujeito à advertência. Caso seja reincidente, ele poderá sofrer autuação e multa em valores que variam de $\mathrm{R} \$ 50$ a $\mathrm{R} \$ 500$, conforme art.84, $\S \S 2^{\circ}$ e $3^{\circ}$ (Brasil, 2013).

Como o Brasil ratificou a Convenção de Basileia em 1992, a proibição de o país importar resíduos sólidos perigosos e rejeitos foi incorporada no art.49 da PNRS.

Apesar dos diversos dispositivos legais regulatórios e sancionadores, há de se considerar que sendo a PNRS uma legislação recente, com novos instrumentos jurídicos, pode-se dizer que a política de gerenciamento de resíduos sólidos no Brasil ainda busca seu aperfeiçoamento e esta sendo "montada" (Bachi, 2013). Por outro lado, haja vista a tardia preocupação brasileira com a questão dos REEEs (já que entre os países pesquisados foi o último a promulgar legislação sobre o tema) revela-se como medida imperativa a regulamentação da logística reversa com a definição dos papéis de cada agente envolvido, como já ocorreu na Suíça. 
Outro problema é que o Brasil não possui um sistema de reciclagem completa dos REEEs, especificamente a etapa de maior agregação de valor da logística reversa de REEEs, a de extração de metais preciosos no processamento final. O processo de logística reversa no país restringe-se às etapas de coleta, desmanche e separação de materiais, tais como plásticos, madeira, vidro, aço. As placas de circuito impresso são trituradas e exportadas para países como Canadá, Bélgica e Cingapura que finalizam o refinamento dos materiais e desfrutam dos maiores benefícios econômicos advindos dos metais preciosos (Oliveira, Bernardes e Gerbase, 2012).

A título de avanço na temática, em 19 de março de 2013 a Associação Brasileira de Normas Técnicas (ABNT) lançou a norma NBR 16156:2013, elaborada pela Comissão de Estudo de Normalização Ambiental para Produtos e Sistemas Elétricos e Eletrônicos do Comitê Brasileiro de Eletricidade (ABNT/CB-03). Essa norma estabelece requisitos para proteção ao meio ambiente e para o controle dos riscos de segurança e saúde no trabalho na atividade de manufatura reversa de resíduos eletroeletrônicos, além de requisitos específicos relacionados com a responsabilidade por substâncias perigosas e a rastreabilidade dos resíduos recebidos (Abnt, 2013). Apesar da ausência de dispositivos com força de lei, essa iniciativa da ABNT demonstra a preocupação com a gestão dos REEEs e o edital do governo promete, em futuro próximo, as primeiras articulações de regras para a logística reversa dos eletroeletrônicos no país. Já o estado de Minas Gerais publicou a Lei no 21421, de 17 de julho de 2014, que entrará em vigor em novembro do mesmo ano. A norma estabelece a obrigatoriedade dos estabelecimentos comerciais e das assistências técnicas, autorizadas pelos fabricantes e importadores de eletroeletrônicos, de manter recipientes para o descarte desses resíduos pelo consumidor, obedecidas as diretrizes da logística reversa dos REEEs e as normas ambientais e de saúde pública pertinentes (Minas gerais, 2014).

Em âmbito nacional, o primeiro edital (Edital n 01/2013) do Ministério do Meio Ambiente (MMA) foi publicado no dia 13/02/13, no Diário Oficial da União, convocando fabricantes, importadores, comerciantes ou distribuidores, por meio de suas entidades representativas, para a elaboração de acordo setorial para a implantação de sistema de logística reversa de produtos eletroeletrônicos e seus componentes. O MMA abriu espaço para propostas de acordo de abrangência nacional que puderam ser apresentadas por fabricantes, importadores, comerciantes ou distribuidores, por meio de suas entidades representativas de âmbito nacional. Da mesma forma, puderam apresentar suas propostas as cooperativas/associações de catadores de materiais recicláveis ou reutilizáveis; as indústrias e entidades dedicadas à reutilização, ao tratamento e à reciclagem; as entidades de representação dos consumidores e o poder público em todas as instâncias. Em 12 de junho de 2013, o prazo foi finalizado com a apresentação de 10 propostas, que até agosto de 2014 estavam em fase de negociação entre o governo e os proponentes (Ribeiro, 2014). Ressalta-se ainda que, o art. 23 do Decreto 7.404/10 (que regulamentou a PNRS) determina alguns requisitos mínimos de conteúdo do acordo setorial. Entretanto, estes requisitos mínimos exigem informações complexas muitas delas conseguidas somente após um significativo tempo de implantação do processo. Algumas destas exigências são: a descrição de toda a operacionalização da logística reversa (ciclos de vida, formas de participação e atividades individualizadas do Estado, sociedade civil organizada e consumidor); a demonstração do cronograma contendo a previsão de evolução até o cumprimento da meta final estabelecida e a avaliação dos impactos sociais e econômicos da implantação da logística reversa. Provavelmente, esse alto nível de exigências, somado aos diferentes interesses envolvidos, esteja dificultando ainda mais a efetividade do acordo.

\section{ANÁLISE COMPARATIVA}

Para a realização da análise comparativa entre as legislações dos países estudados, foram delimitados os elementos presentes em cada país com suas diversas peculiaridades para a exata compreensão das realidades legislativas acerca da gestão de REEE no Brasil e no mundo.

Inicia-se a análise pela concepção do princípio da responsabilidade estendida do produtor presente em quase todas as normas que tratam da gestão do REEE. O que ocorre é que o princípio

Revista de Gestão Social e Ambiental - RGSA, São Paulo, v. 8, n. 1, p. 37-53, jan./abr., 2014. 
do poluidor-pagador presente na legislação chinesa deu suporte à responsabilidade estendida nos EUA, Suíça e Índia e à responsabilidade compartilhada na legislação brasileira. De fato a concepção presente em todos os países é a mesma: a responsabilização do fabricante pelo produto que chega ao fim de sua vida útil, compartilhada entre outros agentes envolvidos na logística de retorno do produto ao ciclo de produção ou sua destinação à reciclagem. Portanto, todos os países definiram em seus textos legais de que a responsabilidade do fabricante não se limita à produção de um bem de qualidade, pois a sustentabilidade dos produtos é qualidade intrínseca desde o processo de sua produção até o seu descarte. A grande diferença é que o principio da responsabilidade compartilhada, adotado pelo Brasil, não afasta a responsabilidade do poder público na gestão dos REEE; pelo contrário, inclui a administração pública na categoria de corresponsável pelos resíduos, juntamente com a iniciativa privada e a sociedade.

Por meio da revisão sistemática de literatura, compreende-se que a responsabilidade estendida do produtor refere-se à figura do fabricante do produto final, e não do produtor isolado, fornecedor de uma única peça do produto eletroeletrônico. Denota-se tal entendimento no momento em que as legislações trazem a expressão "responsabilidade estendida do produtor", como sendo aquele gerador do resíduo e definem sua responsabilidade por toda a vida útil do produto, inclusive por sua reciclagem e disposição final. Se a responsabilidade é do gerador do resíduo não há dúvida que este é o fabricante, responsável pelo produto final que é o aparelho eletroeletrônico comercializado. Corroborando com essa interpretação, em 1992, quando o conceito 'responsabilidade estendida do produtor ou Extended Producer Responsability - EPR' foi publicado pela primeira vez por Lindhqvist, este autor o determina como uma estratégia de proteção ambiental na qual o fabricante do produto é responsável pelo mesmo durante toda a sua vida útil e após, quando da reciclagem e disposição final (Lindhqvist, 2000).

Quanto à definição das responsabilidades dos atores, verifica-se que o modelo brasileiro não é muito diferente do indiano quanto ao tratamento dos REEEs. Se no Brasil, existe uma lei geral que determina a responsabilidade compartilhada entre os atores envolvidos, sem delimitar cada qual, na Índia há uma legislação específica que reconhece a necessidade de se gerir o REEE, mas não define as responsabilidades dos atores, restringindo-se a delimitar a responsabilidade estendida do fabricante. Assim, em ambos os países o lixo eletrônico tem o mesmo tratamento do resíduo domiciliar. No entanto, a Índia (e também Suíça e China) conseguiu um maior avanço legislativo ao limitar a utilização de substâncias perigosas na fabricação dos produtos eletroeletrônicos produzidos naquele país.

Outro aspecto presente nos cenários estudados, com exceção da Suíça, é o mercado ilegal de importação de REEE com substâncias perigosas, frequentes na China e na Índia. Mesmo sendo signatários da Convenção de Basileia, é necessária uma legislação severa interna em cada país a fim de inibir tais importações de REEE advindos principalmente dos Estados Unidos. Por outro lado, ainda existe o dumping do lixo eletrônico que, segundo Vaishnav e Diwan (2013), deveria ser punido com penas privativas de liberdade, uma vez que as multas são insignificantes para os países que cometem tal prática ${ }^{2}$. Da mesma forma que na China e Índia, o Brasil possui indícios de um comércio ilegal de REEE, mas as informações sobre a questão não são confiáveis por ser um mercado irregular, de difícil mensuração, num país de proporção continental e de poucas pesquisas sobre a questão (Oliveira, Bernardes e Gerbase, 2012). O mercado ilegal de resíduos perigosos, que trabalha com procedimentos rústicos de desmontagem de eletroeletrônicos, tem sido responsável pela contaminação das águas (pelos metais pesados), do ar e do solo na China e na Índia (Zeng et al, 2013). Uma pesquisa que aponta um possível caminho para o fim desse comércio ilegal, fruto da falta de cooperação entre os países, é a de Manhardt (2010). O autor aborda a necessidade de uma cooperação internacional para a reciclagem dos REEEs. A justificativa da sua proposta é que os países emergentes possuem grande geração desses resíduos e pouca ou nenhuma tecnologia de reciclagem. Assim, esses países realizariam as etapas preliminares da reciclagem em seu território enviando as partes mais complexas dos REEEs aos países desenvolvidos, possuidores de tecnologia 
de reciclagem; por sua vez, também enviariam seus REEEs para que etapas do pré-tratamento manual dos mesmos fossem realizadas nos países emergentes.

Passa-se agora para a análise das significativas diferenças legislativas quanto ao custeio e a existência de fundo gestor da logística reversa de REEE nos países. No primeiro momento deparase com o papel do Estado e do consumidor para o custeio da logística reversa do REEE. Enquanto na Suíça e em alguns estados americanos (como na Califórnia) o consumidor arca com os custos de boa parte da reciclagem dos REEEs, visto que a taxa paga por eles é revertida ao fundo dos produtores (Suíça) e do governo (Califórnia- EUA), no Brasil e na Índia não existe regulamentação específica definindo o que caberá ou não ao consumidor no custeio da logística reversa. De outro lado, encontra-se a China que exclui o Estado e o consumidor do papel de subsidiar e custear, respectivamente, a reciclagem, sobrecarregando os fabricantes a pagarem taxas a um fundo gerido pelo governo. Com relação a essa peculiaridade chinesa, onde os varejistas não possuem obrigações financeiras de contribuição ao fundo do governo e os fabricantes, apesar de possuírem obrigação legal no pagamento de taxas, não possuem imposição legal quanto à instauração da reciclagem em suas indústrias, Chung e Zhang (2011) destacam que a falta de delimitação legal quanto à distribuição dos recursos financeiros do fundo governamental aos atores envolvidos no ciclo de vida do produto estimula o mercado informal de reciclagem na China, com a presença maciça de catadores. Estes últimos não estão preparados para o manejo ecologicamente adequado dos REEEs. A propósito, no que tange à situação dos catadores, há de se ponderar acerca das realidades chinesa, indiana e brasileira. Se na China e na Índia eles fazem parte de um mercado informal, que inclui crianças e são desprovidos de treinamento para lidar com os REEE, no Brasil não é muito diferente. Apesar do próprio art.33, $\S 3^{\circ}$, III da PNRS determinar que, para a efetividade da logística reversa, o setor privado deve realizar parcerias com as associações de catadores, na prática é diferente. A pesquisa de Lacerda e Pragana (2010) revela que, na cidade de São Paulo, 64\% dos cooperados (associações de catadores) que manejavam REEE não possuíam nenhum tipo de treinamento para tanto. Assim, segundo Dias, Pragana e Dos Santos (2014, p.108), para que esses profissionais possam fazer parte da gestão dos REEEs no Brasil, além da imprescindibilidade da elaboração de políticas públicas voltadas à solução da vulnerabilidade social pela qual sofrem "(...) fica evidenciado que existe a necessidade de prover assistência técnica e capacitação para os catadores".

$\mathrm{Na}$ Tabela 1, são ilustrados os elementos convergentes e divergentes em cada país que puderam ser extraídos da interpretação da revisão bibliográfica.

Tabela 1. Comparação legislativa entre os países

\begin{tabular}{|c|c|c|c|c|c|}
\hline Categorias & Suíça & China & $\begin{array}{c}\text { EUA- } \\
\text { estado da } \\
\text { Califórnia } \\
\end{array}$ & Índia & Brasil \\
\hline Princípio norteador & $\begin{array}{c}\text { Extended Producer } \\
\text { Responsability (EPR) }\end{array}$ & Poluidor-pagador & EPR & EPR & $\begin{array}{c}\text { Resp. } \\
\text { Compartilhada }\end{array}$ \\
\hline Custeio da logística & $\begin{array}{l}\text { Taxas- fabricante e } \\
\text { consumidor }\end{array}$ & $\begin{array}{l}\text { Taxas- fabricantes } \\
\text { e importadores }\end{array}$ & $\begin{array}{c}\text { Taxa- } \\
\text { consumidor }\end{array}$ & Inexistente & Inexistente \\
\hline $\begin{array}{l}\text { Existência de fundo } \\
\text { gestor da logística }\end{array}$ & $\begin{array}{l}\text { Fundo- associação de } \\
\text { produtores }\end{array}$ & Fundo- governo & $\begin{array}{l}\text { Fundo- } \\
\text { governo }\end{array}$ & Inexistente & Inexistente \\
\hline $\begin{array}{c}\text { Definição } \\
\text { responsabilidade atores }\end{array}$ & Sim & $\begin{array}{l}\text { Somente } \\
\text { fabricante }\end{array}$ & $\begin{array}{l}\text { Somente } \\
\text { fabricante }\end{array}$ & Não & Não \\
\hline $\begin{array}{l}\text { Limitação substâncias } \\
\text { perigosas produção }\end{array}$ & Sim & Sim & Não & Sim & Não \\
\hline Comércio ilegal REE & Inexistente & Importador & Exportador & Importador & Incerto \\
\hline
\end{tabular}

Fonte: Elaboração própria, a partir dos dados obtidos na revisão de literatura. 
Importante destacar que apesar das diferenças legislativas em vários aspectos da gestão dos REEEs nos países, conforme a Tabela 01, o papel do Estado enquanto regulador é cumprido em todos os países. A fim de demonstrar sua preocupação com a questão dos REEEs, mesmo que tardia, todos os governos se apressaram a editar normas gerais que responsabilizam o fabricante pelo produto que chega ao fim de sua vida útil. No entanto, a edição de leis sem regulamentação, sem a devida articulação com os participantes da cadeia produtiva de eletroeletrônicos, incluindo os agentes da cadeia de logística reversa de seus resíduos, sem incentivos fiscais e investimento em tecnologia de reciclagem, é uma demonstração do quanto ainda precisa ser negociado entre as partes para que se possa surtir efeitos práticos em termos de gestão dos REEEs. Pela revisão da literatura, percebe-se que a desarticulação existente entre fabricantes, varejistas, recicladores e consumidores na China, Índia, Brasil e Estados Unidos é fruto de uma legislação falha, cheias de lacunas, com ausência de regulação específica acerca dos REEEs. Nesse diapasão, Vaishnav e Diwan (2013) enfatizam que os governos devem fazer parcerias com fabricantes, varejistas e organizações não-governamentais (ONGs) para encontrar soluções para a gestão de REEE e implementar o serviço de reciclagem.

Por fim, destaca-se que o sucesso do modelo suíço se deve muito à experimentação de um procedimento de logística reversa realizado pelas partes interessadas na gestão de REEE na forma de projeto-piloto, anterior à imposição de uma legislação ou alternativa de modificação da norma. A responsabilidade pelo descarte dos produtos eletroeletrônicos no fim da vida útil foi assumida antes mesmo da imposição governamental suíça, por meio de um processo social de "aprender fazendo", pela experiência prática de diferentes atores.

\section{CONSIDERAÇÕES FINAIS}

Depreende-se da interpretação de todo o referencial teórico, que a presença do Estado na regulamentação do mercado de logística reversa de REEE é um fator importante e necessário para o desdobramento do processo de gestão. No entanto, elementos como a participação dos envolvidos nas discussões de uma normatização viável à realidade local (até mesmo antes da edição das leis), incentivos estatais para a reciclagem, a promoção da educação socioambiental do cidadão e a inserção e o treinamento dos catadores para a reciclagem de REEE também são essenciais para o sucesso da gestão de REEE. Em países como China e Índia, que não efetuaram a normatização dos REEEs em um contexto de realidade local e dentro de um processo dialógico entre Estado, setor empresarial e ONGs, não conseguiram desenvolver mecanismos eficazes de controle do descarte e reciclagem dos REEE. No Brasil, apesar dos relevantes esforços do Ministério do Meio Ambiente em promover o acordo setorial entre setor público e privado, o alto volume de exigências contidas no documento, sua tardia discussão e os inúmeros interesses antagônicos das partes envolvidas são fatores desfavoráveis à realização da logística reversa de REEE no país.

Cada país possui alternativas e possibilidades que devem ser exploradas a fim de se alcançar uma melhor gestão dos REEEs. Os Estados Unidos deveriam reconhecer a questão dos REEEs como tema emergente nacional e, por meio de uma legislação federal, definir os principais papéis de cada ator envolvido no ciclo de produção e descarte do eletroeletrônico. A China poderia criar subsídios para que os fabricantes, responsáveis pelo pagamento da taxa ao fundo gestor de REEE, pudessem investir em tecnologias sustentáveis na produção de seus eletroeletrônicos. Na Índia e no Brasil, há urgência na definição legal das responsabilidades específicas dos envolvidos na logística reversa, uma vez que, conforme o art. 34 da PNRS, os acordos setoriais poderão ter abrangência nacional, regional, estadual ou municipal. É importante ressaltar que não há preparo institucional da maioria dos municípios da federação para construir um documento tão complexo, como é o acordo setorial. Nem mesmo a União, após quatro anos de edição da lei, conseguiu finalizar seu acordo setorial com a iniciativa privada, quiçá um município que ainda não realiza a destinação correta de seus resíduos domésticos, realidade esta de 60\% dos municípios brasileiros (Abrelpe, 2014).

Revista de Gestão Social e Ambiental - RGSA, São Paulo, v. 8, n. 1, p. 37-53, jan./abr., 2014. 
O modelo suíço de gestão de REEE é um sucesso no país em razão de uma série de circunstâncias propícias para tanto, tais como cidadãos participativos e conscientes, setor empresarial responsável, disponibilidade de recursos financeiros e tecnologia de reciclagem. Dessa forma, sua mera importação por algum país com realidade socioeconômica divergente não seria a melhor opção. Assim, não se recomenda a aplicação ipsis litteris de nenhum instrumento jurídico internacional. Já que não foi possível a observação de práticas de logística reversa antes da promulgação da lei, é necessária uma regulamentação urgente acerca das responsabilidades de cada agente da logística reversa, com fulcro na realidade socioeconômica, cultural e ambiental do país. A implantação de projetos-piloto de gestão de REEE, tais como parcerias entre governo, setor privado, universidades e ONGS, poderia ser uma opção para o Brasil iniciar suas práticas de formação de cadeias reversas, visto que o prazo de conclusão dos acordos setoriais nacional, regionais, estaduais e municipais pode ser longo.

Os resultados encontrados acerca da discrepância no tratamento legislativo sobre REEE nos países demonstram a necessidade de regulamentações específicas sobre a gestão desses tipos de resíduos e também de uma normatização mundial, já assinalada por Queiruga, González e Lannelongue (2012) e Li et al (2013). Para tanto, é imprescindível uma cooperação internacional para a reciclagem de REEE, conforme defende Manhart (2010). Assim, reportando-se às perguntas de pesquisa, identificou-se a ineficácia da Convenção de Basileia, único acordo internacional que trata dos REEEs em um contexto de proibição do movimento transfronteiriço de resíduos perigosos, que não encontra a adesão do maior gerador de REEE do mundo (Estados Unidos). Conclui-se que, mesmo que cada país realize esforços no alcance de uma eficaz gestão de REEE em seu território, há de se considerar que acordos e tratados internacionais de cooperação deverão ser firmados para que se compartilhem tecnologias de reciclagem e processos de produção e descarte sustentável de REEE. Esta conclusão inspira-se na premissa defendida por Kissinger, Ress e Timmer (2011) de que a sustentabilidade de uma determinada região do mundo depende da produtividade e da sustentabilidade de outras regiões. Já no que se refere ao aspecto jurídico que poderia ser incorporado à PNRS trata-se exatamente da delimitação das responsabilidades de cada ator envolvido na logística reversa, inclusive quanto ao custeio do processo, como acontece na Suíça. Ainda, as experiências malsucedidas de China e Índia com o mercado informal de REEE sinalizam a importância do treinamento dos catadores e de parcerias entre setor privado e associações.

Por meio de uma desk research, procurou-se realizar uma interpretação legislativa acerca da gestão de REEE de alguns países para integrar as escassas pesquisas brasileiras sobre o assunto. Tratando-se de uma revisão de literatura, com recorte temporal e com delimitação de alguns países para estudo, tem suas limitações como qualquer outra. Novas pesquisas, com a adoção de outros recortes temporais e a escolha de outros países podem sinalizar novas análises legislativas acerca da gestão de REEE no mundo.

\section{NOTAS}

\footnotetext{
${ }^{1}$ A externalização de custos, segundo Souza et al (2009), é um meio utilizado para se reduzir os custos totais da empresa e aumentar sua competitividade, transferindo para terceiros parte de suas atividades, até então realizadas internamente.

${ }^{2}$ O Dumping do lixo eletrônico é prática utilizada por alguns países que vendem aparelhos eletroeletrônicos, como computadores, destinados à reciclagem, por preços menores aos países subdesenvolvidos (Greenpeace, 2013).
}

\section{REFERÊNCIAS}

ABNT- Associação Brasileira de Normas Técnicas. NBR16156. (2013) Resíduos de Equipamentos Eletroeletrônicos- Requisitos para atividade de manufatura reversa. Rio de Janeiro.

Abrelpe.(2014) Notícias. Lançado panorama de 2013. Recuperado em 14 de agosto de 2014, de <http://www.abrelpe.org.br/noticias_detalhe.cfm?NoticiasID=2091>. 
Bachi, M. H (2013). Resíduos tecnológicos: a relação dos resíduos eletroeletrônicos com a legislação do Brasil. Revista Brasileira de Gestão Ambiental, 7(1), 01-05.

Basel Convention. (2013) Presidência da República, Casa Civil, Subchefia para Assuntos Jurídicos. Decreto $n$. $n^{o}$ 7.404/2010. Regulamenta a Lei $n^{-} 12.305$, de 2 de agosto de 2010, que institui a Política Nacional de Resíduos Sólidos. Recuperado em 23 de junho de 2013, de <http://www.planalto.gov.br/ccivil_03/_ato2007-2010/2010/Decreto/D7404.htm>. Recuperado em 22 de julho de 2013, de<http://www.basel.int.>

Brasil.

. Presidência da República, Casa Civil, Subchefia para Assuntos Jurídicos. Lei Federal $n$. 12.305/2010. Institui a Política Nacional de Resíduos Sólidos. Recuperado em 23 de junho de 2013, de <http://www.planalto.gov.br/ccivil_03/_ato2007-2010/2010/lei/112305.htm>.

Chung, S-S; Zhang, C (2011) An evaluation of legislative measures on electrical and electronic waste in the People's Republic of China. Waste Management, (31), 2638-2646.

Dias, S.L.F.G., Pragana, V.R., Dos Santos, M.C.L (2014) Catadores: uma reflexão sobre os aspectos socioambientais da gestão de Resíduos dos Equipamentos Eletroeletrônicos. In: Carvalho, T.C.M.B., Xavier, L.H. (orgs). Gestão de Resíduos eletroeletrônicos: uma abordagem prática para a sustentabilidade. Rio de Janeiro: Elsevier,149-164.

Demajorovic, J., Migliano, J (2013) Política Nacional de Resíduos Sólidos e suas implicações na cadeia da logística reversa de microcomputadores no Brasil. Gestão \& Regionalidade, 29(87).

Dwivedy, M; Mittal, R.K (2012) An investigation into e-waste flows in India. Journal of Cleaner Production, (37), 229-242.

Feam. Fundação Estadual do Meio Ambiente. Feam lança estudo sobre resíduos eletroeletrônicos. Recuperado em 24 de junho de 2013, de <http://www.feam.br/noticias/1/614-feam-lanca-estudosobre-residuos-eletroeletronicos>.

Franco, R. G. F.; Lange, L. C (2011) Estimativa do fluxo dos resíduos de equipamentos elétricos e eletrônicos no município de Belo Horizonte, Minas Gerais, Brasil. Engenharia Sanitária Ambiental, 16(1), 73-82.

Gidarakos, E., Basu, S., Rajeshwari, K.V., Dimitrakakis, E., Johri, C. R (2012) E-waste recycling environmental contamination: Mandoli, India. Waste and Resource Management, 165, 45-52.

Greenpeace (2013) Undercover operation exposes illegal dumping of e-waste in Nigeria. Recuperado em 10 de agosto de 2013, de <http://www.greenpeace.org/international/en/news/features/e-waste-nigeria180209>

Herat, S., Agamuthu, P (2012) E-waste: a problem or an opportunity? Review of issues, challenges and solutions in Asian countries. Waste Management \& Research, (30), 1113-1129.

Khetriwal, D.S, KraeuchI, P., Widmer, R (2009) Producer responsibility for e-waste management: key issues for consideration e learning from the swiss experience. Journal of Environmental Management, (90), 153-165.

Kissinger, M., Rees, W. E., Timmer, V.(2011) Interregional sustainability: governance and policy in an ecologically interdependent world. Environmental science \& policy, (14), 965-976. 
Kojima, M., Yoshida, A., Sasaki, S. (2009) Difficulties in applying extended producer responsibility policies in developing countries: case studies in e-waste recycling in China and Thailand. Journal of Material Cycles and Waste Management, (11), 263- 269.

Kyle, B. (2013) EPA's new figures show most e-waste still getting trashed. Electronics Take Back Coalition. Recuperado em 23 de julho de 2013, de <http://www.electronicstakeback.com>.

Lacerda, P.S., Pragana, V.R (2010) Resíduos de equipamentos eletroeletrônicos: caracterização e fluxo pós-descarte em centros de triagem do município de São Paulo. Projeto de Pesquisa de Iniciação Científica. Faculdade de Saúde Pública. Universidade São Paulo.

Lepawsky, J (2012) Legal geographies of e-waste legislation in Canada and the US: Jurisdiction, responsibility and the taboo of production. Geoforum, (43), 1194-1206.

Li, J., Lopez, B. N., Liu, L., Zhao, N.,Y., K., Zheng, L (2013) Regional or global WEEE recycling. Where to go? Waste Management, (33), 923-934.

Lindhqvist, T.(2000) Extended Producer Responsibility in Cleaner Production. Doctor Dissertation (Doctorate in Industrial Environmental Economics) - Lund University, Sweden.

Manhart, A (2010). International cooperation for metal recycling from waste electrical and electronic equipment. Journal of Industrial Ecology, 15, 13- 30.

Oliveira, C. R; Bernardes, A. M.; Gerbase, A. E (2012). Collection and recycling of electronic scrap: A worldwide overview and comparison with the Brazilian situation. Waste Management. Elsevier, 32, ed. 8, 1592-1610.

Ongondo, F.O., Williams, I.D., Cherret, T.J (2011). How are WEEE doing? A global review of the management of electrical and electronic wastes. Waste Management, 714-730.

Pnuma Programa das Nações Unidas para o meio ambiente. Recuperado em 31 de julho de 2013, de $<$ http://www.pnuma.org.br>.

Queiruga D., González, B. G., Lannelongue G (2012) Evolution of the electronic waste management system in Spain. Journal of Cleaner Production, (24), 56- 65.

Ribeiro, R.(2014) Política de resíduos sólidos apresenta resultados em 4 anos. InforMMA: notícias Brasília. Recuperado em 13 de agosto de 2014, de <http://www.mma.gov.br/informma/item/10272pol\%C3\%ADtica-de-res\%C3\%ADduos-s\%C3\%B3lidos-apresenta-resultados-em-4-anos>.

Robinson, B. H (2009) E-waste: an assessment of global production and environmental impacts. Science of the Total Environment, (408), 183-191.

Souza, M.C. A. F., Bacic, M. J., Bernardes, J. M.R (2009) A gestão estratégia das compras como política para reduzir custos. Gestão \& Regionalidade, 25(74), 35-47.

Tong, X., Yan, L.(2013). From legal transplants to sustainable transition: extended producer responsibility in chinese waste electrical and electronic equipment management. Journal of Industrial Ecology, Yale University, (17), 02. 
Towsend, T. G (2011). Environmental issues and management strategies for waste electronic and electrical equipment. Air \& Waste Manage, (61), 587-610.

Vaishnav, D., Diwan, R (2013). E-Waste management - An overview. Recent Research in Science and Technology, (05), 92-97.

Wager, P.A., Hischier, R. Eugster, M (2011) Environmental impacts of the Swiss collection and recovery systems for Waste Electrical and Electronic Equipment (WEEE): A follow-up. Science of the Total Environment, Elsevier, (409), 1746-1756.

Wagner, T.P (2009) Shared responsibility for managing electronic waste: a case study of Maine, USA. Waste Management, (29), 3014-3021.

Wang, F., Leung, A. O.W., Wu, S.C., Yang, M.S., Wong, M.H (2009) Chemical and ecotoxicological analyses of sediments and elutriates of contaminated rivers due to e-waste recycling activities using a diverse battery of bioassays. Environmental Pollution, 157(7), 20822090.

Zeng, X., LI, J., Stevels, A.L.N., Liu, L (2013) Perspective of electronic waste management in China based on a legislation comparison between China and the EU. Journal of Cleaner Production, (51), 80-87.

Data da submissão: 09/01/2014

Data da publicação: 30/04/2014 